\title{
Laboratory Test Abnormalities are Common in Polymyositis and Dermatomyositis and Differ Among Clinical and Demographic Groups
}

\author{
Rita Volochayev ${ }^{1}$, Gyorgy Csako², Robert Wesley ${ }^{2}$, Lisa G. Rider ${ }^{1}$ and Frederick W. Miller ${ }^{*}, 1$ \\ ${ }^{I}$ Environmental Autoimmunity Group, Program of Clinical Research, National Institute of Environmental Health \\ Sciences, National Institutes of Health, HHS, Bethesda, Maryland, USA \\ ${ }^{2}$ The Clinical Center, National Institutes of Health, HHS, Bethesda, Maryland, USA
}

\begin{abstract}
Objective: Given the difficulties regarding the interpretation of common laboratory test results in polymyositis $(\mathrm{PM})$ and dermatomyositis (DM) in clinical practice, we assessed their range of abnormalities, differences among phenotypes and interrelationships in a large referral population.

Methods: We retrospectively assessed 20 commonly measured blood laboratory tests in 620 well-defined PM/DM patients at different stages of illness and treatment to determine the frequency, range of abnormalities and correlations among clinical, gender, racial and age phenotypes.

Results: Myositis patients at various stages of their disease showed frequent elevations of the serum activities of creatine kinase $(51 \%)$, alanine aminotransferase (43\%), aspartate aminotransferase (51\%), lactate dehydrogenase (60\%), aldolase $(65 \%)$ and myoglobin levels $(48 \%)$ as expected. Other frequent abnormalities, however, included elevated high white blood cell counts (36\%), low lymphocyte counts (37\%), low hematocrit levels (29\%), low albumin levels (22\%), high creatine kinase MB isoenzyme fractions (52\%), high erythrocyte sedimentation rates (33\%) and high IgM and IgG levels (16\% and $18 \%$, respectively). Many of these tests significantly differed among the clinical, gender, racial and age groups. Significant correlations were also found among a number of these laboratory tests, particularly in the serum activity levels of creatine kinase, the transaminases, lactate dehydrogenase and aldolase.

Conclusion: Laboratory test abnormalities are common in PM/DM. Knowledge of the range of these expected abnormalities in different myositis phenotypes, gender and age groups and their correlations should assist clinicians in better interpretation of these test results, allow for a clearer understanding what level of abnormality warrants further evaluation for liver or other diseases, and may avoid unnecessary laboratory or other testing.
\end{abstract}

Keywords: Myositis, phenotypes, laboratory testing.

\section{INTRODUCTION}

The idiopathic inflammatory myopathies (IIM) are a group of autoimmune muscle diseases of which polymyositis (PM) and dermatomyositis (DM) are the most frequently recognized forms [1]. Although the IIM are the most commonly acquired muscle diseases in adults, they are still rare in the general population with an estimated annual incidence of only 10 new cases per million persons. These diseases are difficult to diagnose and categorize into predictive groups [2]. Their diagnosis and treatment are often delayed because patients initially present with vague or nonspecific symptoms such as fatigue, myalgias, and arthralgias, which are also common in other types of illnesses [3].

The serum activity level of creatine kinase (CK) is the most commonly performed enzyme test for the diagnosis and monitoring of myositis $[1,4,5]$. This is due to the relative muscle specificity of the enzyme and the infrequent

\footnotetext{
*Address correspondence to this author at the Environmental Autoimmunity Group, National Institute of Environmental Health Sciences, National Institutes of Health, CRC 4-2352, MSC 1301, 10 Center Drive, Bethesda, MD 20892-1301, USA; Tel: 301-451-6273; Fax: 301-451-5585;

E-mail: millerf@mail.nih.gov
}

involvement of other organs that can generate CK (brain, cardiac muscle) in patients with IIM [6]. Although elevations of $\mathrm{CK}$ and other serum muscle enzyme activities are used as one criterion for diagnosis [7], few studies have assessed the other laboratory blood tests often ordered in myositis patients, leading to misconceptions and a lack of understanding of the meaning of the test results obtained [5]. Our anecdotal experience is that many unnecessary tests are performed on myositis patients to assess for other conditions in response to laboratory abnormalities that are actually the result of the myositis. For example, elevations of serum activities of the so called "liver enzymes", the transaminases and lactate dehydrogenase (LD) in myositis patients due to myoblast activation, have resulted, and in our experience continue to result, in the misdiagnosis of liver disease and inappropriate liver biopsies [1]. Likewise, elevations in the serum activity of the CK-MB fraction isoenzyme (CK-MB) can result in the misdiagnosis of myocardial infarction [8]. The current study was conducted to address these issues by assessing the results of 20 routine blood laboratory tests from a large group of myositis subjects evaluated at the National Institutes of Health (NIH). This population would be representative of a referral population at different stages of disease progression and with various levels of disease activity undergoing different treatments. Our findings of 
frequent abnormalities in these tests and differences among phenotypes should aid clinicians in better understanding the utility of various laboratory tests in myositis patients seen in clinical practice.

\section{MATERIALS AND METHODOLOGY}

Patient population. The participants in the study were 620 patients (181 men and 439 women; 351 with PM and 269 with DM; 427 Caucasians, 130 blacks and 63 of other races) of the initial 800 consecutive individuals with myopathies who were evaluated in natural history and therapeutic research protocols in the National Institute of Arthritis and Musculoskeletal and Skin Diseases (NIAMS) between 1985 and 2005. All subjects signed informed consent for NIAMS institutional review board approved protocols. Most subjects were referred for recommendations for therapy, possible inclusion in therapeutic trials or for diagnostic purposes. Selection criteria for this study included adult patients with the diagnosis of PM or DM on the basis of the exclusion of other forms of myopathy and meeting probable or definite Bohan and Peter criteria [9], and who had results for at least 15 of the 20 laboratory tests commonly assessed in myositis patients at the NIH. All laboratory tests were performed in the NIH Department of Laboratory Medicine of the NIH Clinical Center and data from the first time that at least 15 concurrent laboratory test values were available were used. Subjects with criteria for possible myositis $(\mathrm{n}=35)$, muscular dystrophies $(\mathrm{n}=29)$, inclusion body myositis $(\mathrm{n}=28)$, cancer-associated myositis $(n=9)$, juvenile myositis $(n=5)$ metabolic myopathies $(n=4)$, PM or DM but fewer than 15 concurrent laboratory tests available $(n=27)$, and undefined myopathies $(n=43)$ were excluded from study.

Data recording. Data collected in this retrospective cohort study included demographics (age, gender and race), clinical information (the presence of Gottron's papules or sign or Heliotrope rash to define DM), and 20 laboratory tests commonly performed on myositis patients at the NIH. The laboratory tests included were serum levels of albumin, creatinine, aldolase, CK (total level and isoenzymes CK-BB, CK-MB, CK-MM), quantitative immunoglobulins (IgG, IgM and IgA levels), erythrocyte sedimentation rate (ESR), total white blood cell count (WBC) and differential (including percent basophils, lymphocytes and polymorphonuclear leukocytes), hematocrit, aspartate aminotransferase (AST), alanine aminotransferase (ALT), LD, and myoglobin. When the normal reference ranges changed during the study period, laboratory results were expressed in relation to the upper limits of the normal range and recalculated based upon the current normal range.

Statistical analysis. Data analyses were performed using Statistical Package for the Social Sciences (SPSS) version 10.0 (SPSS, Inc., Chicago IL.), following the SPSS Base 10.0 for Windows User's Guide (SPSS Inc., Chicago IL.), and Stata version 11 (Austin, TX). Because analyses using the Shapiro-Wilk test showed that all 20 of the laboratory measurements were not normally distributed, the summary measures reported are medians and interquartile ranges. The proportions of subjects with abnormally high and low values were calculated based on the normal ranges established for healthy individuals at the NIH Department of Laboratory
Medicine (established to cover 95\% of normal individuals). Due to the non-normality of the distribution of measurements, the primary analyses to assess possible differences in laboratory tests in demographic groups (i.e., male and female gender; Caucasian, black, and other races; age tercile groups of $<37,37-50$, and $>50$ years) and in clinical groups (i.e., PM and DM), were performed via the nonparametric Wilcoxon rank sum test (for two groups), the Kruskal-Wallis test (for the three unordered racial categories), or Kuzick's nonparametric trend test ("nptrend" test in Stata) for the three ordered age categories.

Correlations of selected laboratory values used Spearman's rank correlation to accommodate the non-normality of the values. For this study we defined Rho correlations as falling into four categories: $0.7-1.0=$ high correlation; $0.5-<0.7=$ moderate correlation; $0.3-<0.5=$ low correlation; and $<0.3=$ little correlation [10].

Additional analyses used multiway ANOVA or prediction intervals based on linear regression models. For these analyses either logarithms of the raw values were used (14 of the parameters) or the inverse hyperbolic sine transformed-values were used (for six parameters: basophils, lymphocytes, Polys, ESR, and the three CK isoenzyme values; this transformation is very similar to a $\log$ transformation, but is more flexible in allowing 0 , or even negative, values). As indicated by the Shapiro-Wilk test and other confirmatory tests, these transformations greatly reduced the skewness of the distributions and resulted in more Gaussian-like distributions. The multiway ANOVA analyses were used to confirm the primary univariate group comparisons, by including in each analysis gender, race, and diagnosis. In assessing the effect of age, all three factors of gender, race, and diagnoses were taken into account.

Because this was an exploratory study, a two-sided $p$ value of $<0.05$ was considered significant for these analyses, with no correction for multiple comparisons.

\section{RESULTS}

Laboratory test abnormalities in IIM patients. As expected, many of the IIM patients frequently had various enzyme values above the normal limits (Table 1). The abnormal laboratory results included skeletal muscle markers such as aldolase, CK, CK-MB, LD, myoglobin, and transaminases (ALT and AST), as well as acute and chronic inflammatory markers (WBC count, polymorphonuclear leukocytes, ESR, and immunoglobulins IgG and IgM).

In contrast, a number of other test results were frequently below the normal range. Of these, low CK-MM levels, lymphocyte counts, and creatinine levels have been previously reported in patients with IIM $[5,11,12]$. Low hematocrit and serum albumin levels, however, have not been systematically described in myositis.

Differences in laboratory test results among gender, race, age, and IIM clinical groups. CK levels were significantly higher in men compared to women, in blacks compared to Caucasians and in PM compared to DM (Fig. 1), as previously described [13]. CK-MB levels were also significantly higher in men compared to women with IIM. The median aldolase levels were also above normal in all groups and they were significantly higher in men, blacks and 
Table 1. Laboratory Test Results for Myositis Patients in the Study*

\begin{tabular}{|c|c|c|c|c|c|c|c|c|}
\hline Test & $\begin{array}{c}\text { Normal Range, } \\
\text { Units }\end{array}$ & $\begin{array}{c}\text { Number } \\
\text { Tested }\end{array}$ & $\begin{array}{l}\text { \% Below Lower } \\
\text { Limit of Normal }\end{array}$ & $\%$ Normal & $\begin{array}{l}\text { \% Above Upper } \\
\text { Limit of Normal }\end{array}$ & $25 \%$ Level & $\begin{array}{c}50 \% \text { (Median) } \\
\text { Level }\end{array}$ & $75 \%$ Level \\
\hline Aldolase & $1-6 \mathrm{U} / \mathrm{L}$ & 507 & 0.0 & 39.6 & 60.4 & 5.0 & 9.0 & 21.0 \\
\hline ALT & $6-41 \mathrm{U} / \mathrm{L}$ & 618 & 0.3 & 56.6 & 43.0 & 22.0 & 35.0 & 68.0 \\
\hline AST & $9-34 \mathrm{U} / \mathrm{L}$ & 617 & 0.5 & 49.0 & 50.6 & 23.0 & 35.0 & 65.0 \\
\hline $\mathrm{CK}$ & $\begin{array}{l}\text { F } 38-252 \mathrm{U} / \mathrm{L} \\
\text { M 52-386 U/L }\end{array}$ & 613 & 7.2 & 42.4 & 50.4 & 82.0 & 297.0 & 1136.0 \\
\hline CK-MM & $97-100 \%$ & 350 & 63.7 & 36.0 & 0.3 & 89.0 & 95.0 & 100.0 \\
\hline CK-MB & $0-3 \%$ & 355 & 0.6 & 47.0 & 52.4 & 0.0 & 3.0 & 6.0 \\
\hline CK-BB & $0 \%$ & 355 & 0.0 & 96.6 & 3.4 & 0.0 & 0.0 & 0.0 \\
\hline $\mathrm{LD}$ & $113-226 \mathrm{U} / \mathrm{L}$ & 577 & 0.5 & 35.0 & 64.5 & 200.0 & 264.0 & 392.0 \\
\hline Myoglobin & $0 \mathrm{ng} / \mathrm{ml}$ & 269 & 0.0 & 52.0 & 48.0 & 30.0 & 64.0 & 246.0 \\
\hline Albumin & $3.7-4.7 \mathrm{~g} / \mathrm{dL}$ & 602 & 21.9 & 73.8 & 4.3 & 3.7 & 4.1 & 4.4 \\
\hline Creatinine & $\begin{array}{l}\text { F } 0.56-1.16 \mathrm{mg} / \mathrm{dL} \\
\text { M } 0.77-1.19 \mathrm{mg} / \mathrm{dL}\end{array}$ & 618 & 34.1 & 62.9 & 2.9 & 0.6 & 0.8 & 1.0 \\
\hline WBC & $\begin{array}{l}\text { F } 3.98-10.04 \mathrm{k} / \mu \mathrm{L} \\
\text { M } 4.29-9.07 \mathrm{k} / \mu \mathrm{L}\end{array}$ & 619 & 2.8 & 61.7 & 35.5 & 5.8 & 8.2 & 11.5 \\
\hline Basophils & $\begin{array}{l}\text { F } 0.1-1.2 \% \\
\text { M } 0.2-1.2 \%\end{array}$ & 609 & 0.0 & 99.8 & 0.2 & 0.0 & 0.2 & 1.0 \\
\hline Lymphocytes & $\begin{array}{l}\text { F } 19.3-51.7 \% \\
\text { M } 21.8-53.1 \%\end{array}$ & 607 & 37.4 & 61.9 & 0.7 & 9.9 & 18.0 & 28.0 \\
\hline Polys & $\begin{array}{l}\text { F } 1.56-6.13 \% \\
\text { M } 1.78-5.38 \%\end{array}$ & 606 & 1.2 & 62.5 & 36.3 & 59.5 & 71.0 & 83.0 \\
\hline Hematocrit & $\begin{array}{l}\text { F } 34.1-44.9 \% \\
\text { M } 40.1-51.0 \%\end{array}$ & 619 & 28.8 & 65.6 & 5.7 & 36.5 & 39.5 & 42.4 \\
\hline ESR & $\begin{array}{l}\text { F } 0-42 \mathrm{~mm} / \text { hour } \\
\text { M } 0.25 \mathrm{~mm} / \text { hour }\end{array}$ & 604 & 1.7 & 65.4 & 33.0 & 12.0 & 24.5 & 47.0 \\
\hline $\operatorname{IgG}$ & $642-1730 \mathrm{mg} / \mathrm{dL}$ & 536 & 4.9 & 77.4 & 17.7 & 891.5 & 1120.0 & 1400.0 \\
\hline $\operatorname{IgM}$ & $34-342 \mathrm{mg} / \mathrm{dL}$ & 536 & 0.8 & 83.8 & 15.5 & 95.0 & 142.0 & 213.0 \\
\hline $\operatorname{IgA}$ & $91-499 \mathrm{mg} / \mathrm{dL}$ & 536 & 1.5 & 90.5 & 8.0 & 149.0 & 204.0 & 280.0 \\
\hline
\end{tabular}

*Abbreviations: creatine kinase total level (CK) and isoenzyme fractions (CK-MM, CK-MB, CK-BB), quantitative immunoglobulins (IgG, IgM and IgA), erythrocyte sedimentation rate (ESR), total white blood cell count (WBC) and differential (including percent polymorphonuclear leukocytes (Polys)), alanine aminotransferase (ALT), aspartate aminotransferase (AST), and lactate dehydrogenase (LD), female (F), male (M).

in patients with PM. Age also seemed to impact the aldolase levels. There was a significant trend for values to go down in older age groups primarily due to the oldest age tercile $(>50$ years) being significantly lower than the other two terciles. Similar age-related trends were seen in all three skeletal muscle markers (CK, CK-MB and aldolase; Fig. 1).

The median values tended to be borderline high for both AST and ALT in most groups, while above normal for LD in all groups (Fig. 2). There were statistically significant differences in gender, race and clinical diagnosis groups for AST and ALT. Men had higher levels of these enzymes than women, as has been described in healthy populations [14]. On the other hand, LD was significantly higher only in blacks and in patients with PM. Higher serum LD in blacks compared to Caucasians is consistent with the observation that enzymes catalyzing reactions in phosphagenic (CK) and glycolytic (e.g., LD) metabolic pathways have significantly higher activities (by 30-40\%) in skeletal muscle biopsy tissue of Africans compared to Caucasians [15].
Although all subgroup medians fell within the respective normal reference intervals, there were several statistically significant differences for WBC count, percent lymphocytes, and ESR (Fig. 3). WBCs were higher in males than females and in Caucasians than blacks, while lymphocytes were lower in males than females and tended to decrease with age. This conflicts with data in other populations describing higher WBC counts in women [16]. ESR levels were higher in females compared to males and in blacks compared to Caucasians, as previously reported for healthy populations [17].

The median values were within the respective reference intervals for serum albumin and hematocrit, but they were at the low end of the reference interval for serum creatinine, consistent with the expected loss of muscle mass in myositis patients. On the other hand, serum albumin levels were significantly higher in Caucasians than blacks and significantly lower in PM compared to DM patients. Similar to a healthy population, serum creatinine levels were 


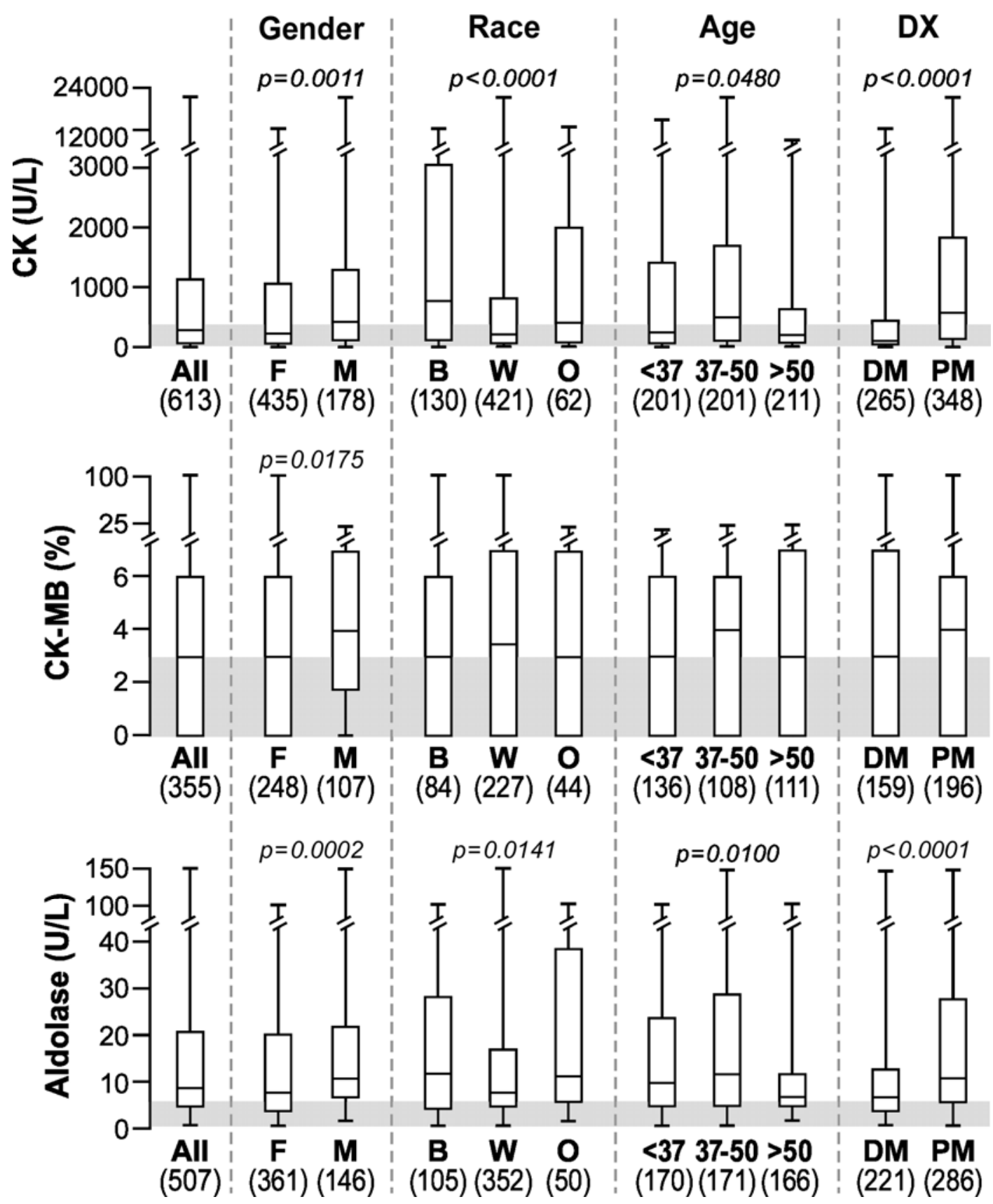

Fig. (1). Box plots showing the median, $25^{\text {th }}$ and $75^{\text {th }}$ percentiles and highest and lowest values for CK, CK-MB and aldolase in all myositis patients and differences among groups. The shaded area depicts the normal range.*

*Abbreviations: Dx, diagnosis; DM, dermatomyositis; PM, polymyositis; B, black; W, white, Caucasian; O, other; rest per Table 1.

significantly higher in men than women with IIM, likely due to the larger muscle mass in men. Creatinine levels were higher in those older than 50 years, possibly due to declining renal function. The hematocrit was significantly higher in males compared to females with IIM, as described in healthy populations [18].

In order to assess the relative contribution of diagnosis, age, gender and race to the differences in certain laboratory measures, we compared P-values based on the log values of laboratory measures. These analyses showed that $\mathrm{CK}$ and aldolase were most different among the diagnostic groups ( $\mathrm{P}$ $=1.2 \times 10^{-17}$ and $\mathrm{P}=5.3 \times 10^{-9}$, respectively). Nonetheless,
$\mathrm{CK}$ and aldolase also differed among races $\left(\mathrm{P}=4.1 \times 10^{-9}\right.$ and $\mathrm{P}=0.0086$, respectively), and by gender $(\mathrm{P}=0.002$ and $\mathrm{P}=0.005$, respectively), but both of these were less significant than the differences among diagnostic groups. Hematocrit differed most between males and females $(\mathrm{P}=$ $\left.8.4 \times 10^{-13}\right)$, but less so among races $(\mathrm{P}=0.00008)$, age groups $(\mathrm{P}=0.001)$ and diagnostic groups $(\mathrm{P}=0.035)$.

The parametric multiway ANOVA analyses, always taking into account the factors of gender, race, age and diagnosis, confirmed all of the statistically significant univariable results, with confirmatory $\mathrm{P}$-values $<0.05$, except in the following 3 cases where the multivariable P-value did 


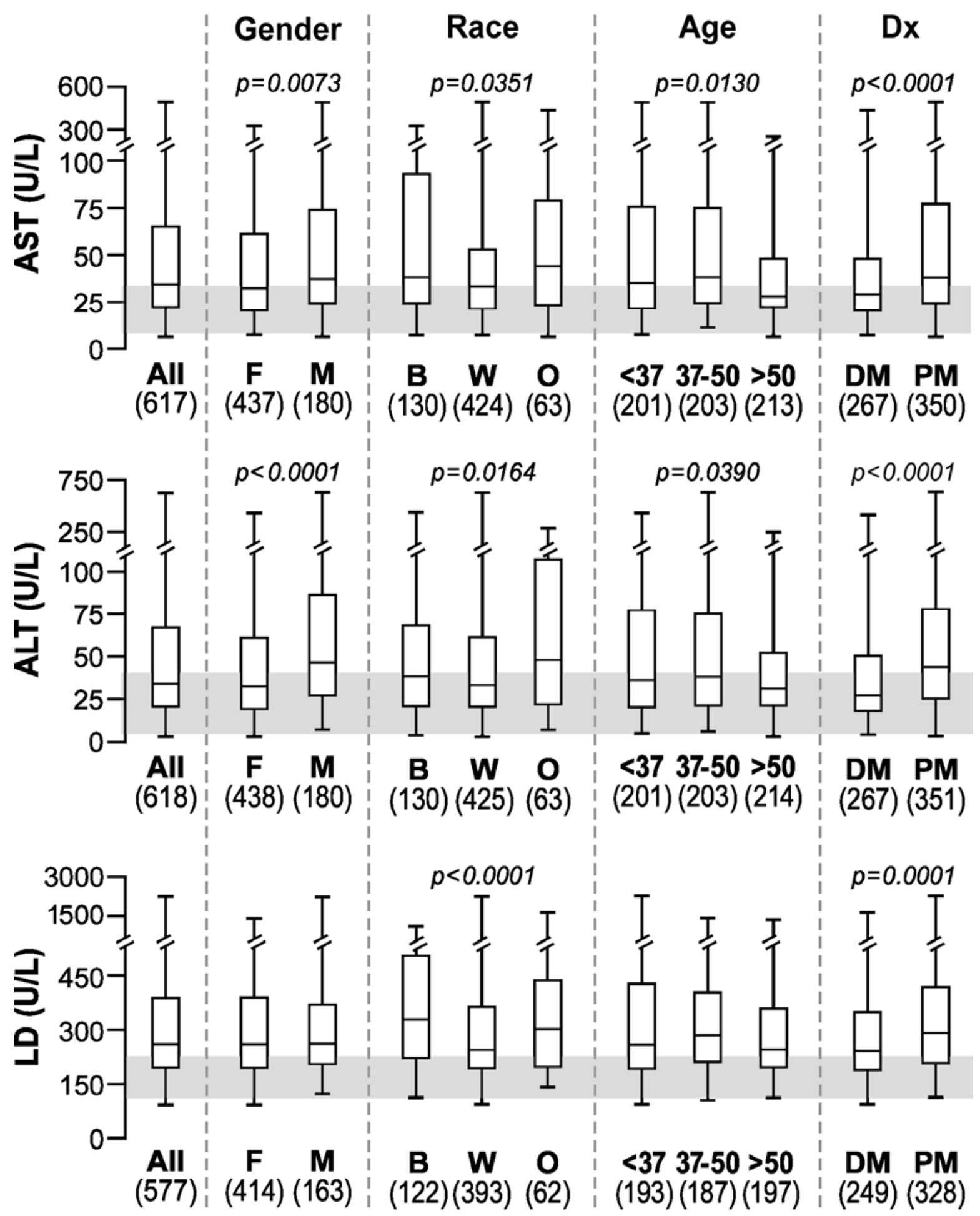

Fig. (2). Box plots showing the median, $25^{\text {th }}$ and $75^{\text {th }}$ percentiles and highest and lowest values for AST, ALT and LD in all myositis patients and differences among groups. The shaded area depicts the normal range*.

*Abbreviations: per Table 1 and Fig. (1).

not reach significance: (1) the effect of age on lymphocytes $(\mathrm{P}=0.082) ;(2)$ the effect of gender on WBCs $(\mathrm{P}=0.088)$; and $(3)$ the effect of gender on lymphocytes $(\mathrm{P}=0.061)$ were not significant. The number and magnitude of these changes in P-values are quite minor, and serve to strongly confirm the primary univariable results.
Correlations among laboratory test results. A number of significant correlations among the laboratory tests studied were identified in the IIM (see Table $\mathbf{2}$ where only correlations greater than 0.5 in absolute value are shown). Moderate to high correlations were observed among aldolase, ALT, AST, CK, LD, myoglobin, Polys, and WBC. Muscle enzymes and muscle breakdown products all 


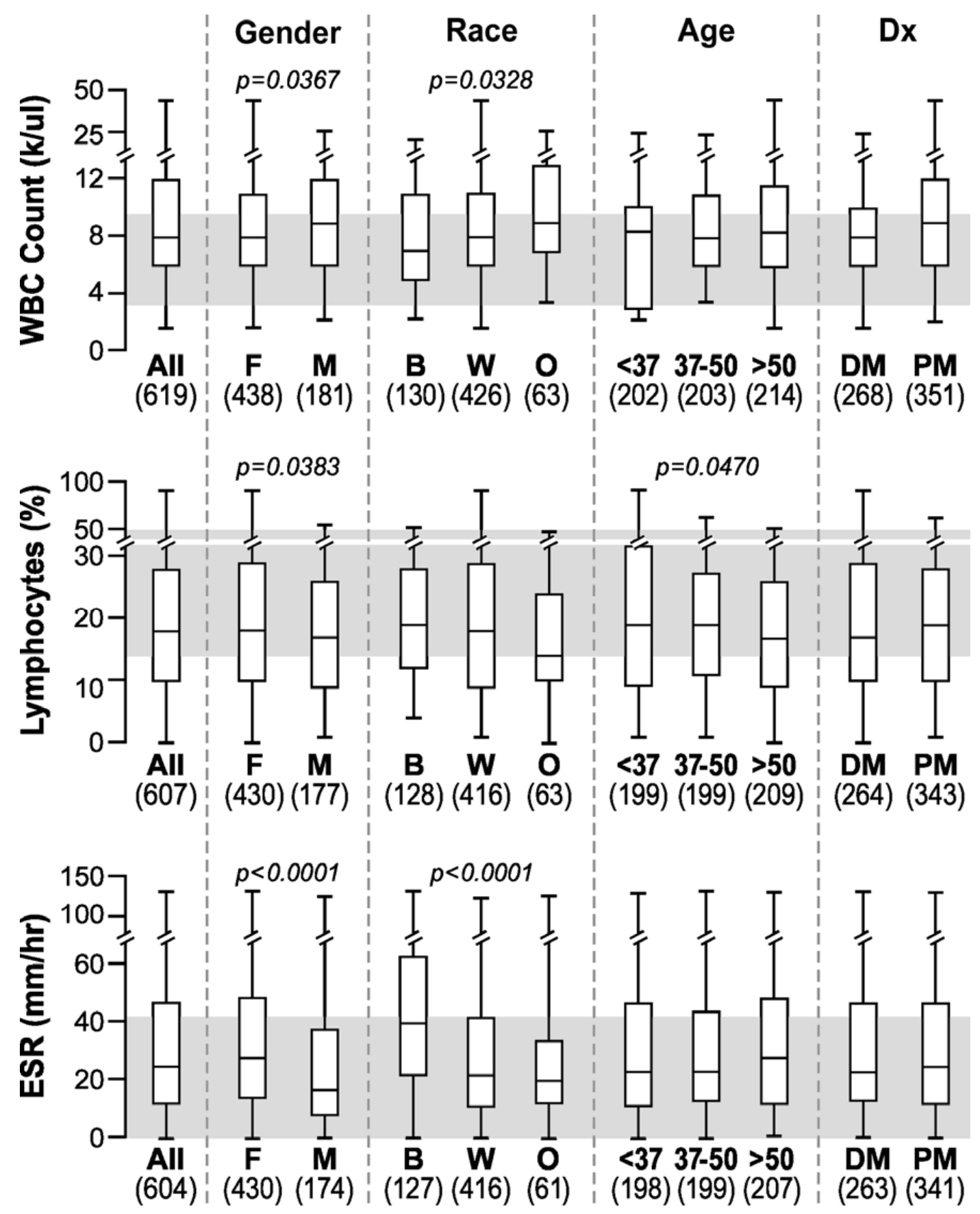

Fig. (3). Box plots showing the median, $25^{\text {th }}$ and $75^{\text {th }}$ percentiles and highest and lowest values for WBC count, lymphocytes and ESR in all myositis patients and differences among groups. The shaded area depicts the normal range*.

*Abbreviations: per Table 1 and Fig. (1).

correlated highly, as expected. Aldolase correlated significantly with 14 of the other laboratory tests and particularly strongly with ALT, AST, CK, LD, and myoglobin. A moderate correlation was found between Polys and WBCs. Lower correlations were found among the other laboratory tests.

Fig. (4) displays scatter plots for CK levels with aldolase, ALT, AST and LD values for all patients. The plots show the $95 \%$ and $99 \%$ prediction intervals of CK with each of these four tests, thus providing guidance to clinicians of when a test result may be considered to be outside the expected range for patients with myositis and when further evaluation for liver disease may be warranted. Although only limited data were available in this retrospective study, the medical records of the 17 individuals who had ALT, AST or LD levels higher than the $99 \%$ prediction interval were examined to assess the possibility of liver disease. Of these 17 individuals, four had documented liver disease (one each 
Table 2. Summary of Moderately to Highly Correlated Laboratory Results*

\begin{tabular}{|c|c|c|c|}
\hline First Test & Correlated Test & $\mathbf{n}$ & Rho \\
\hline \multirow[t]{5}{*}{ Aldolase } & ALT & 506 & 0.77 \\
\hline & AST & 506 & 0.80 \\
\hline & CK & 505 & 0.82 \\
\hline & LD & 472 & 0.78 \\
\hline & Myoglobin & 177 & 0.82 \\
\hline \multirow[t]{5}{*}{ ALT } & Aldolase & 506 & 0.77 \\
\hline & AST & 617 & 0.86 \\
\hline & CK & 612 & 0.70 \\
\hline & LD & 576 & 0.67 \\
\hline & Myoglobin & 268 & 0.73 \\
\hline \multirow[t]{4}{*}{ AST } & $\begin{array}{c}\text { Aldolase } \\
\text { ALT }\end{array}$ & $\begin{array}{l}506 \\
617\end{array}$ & $\begin{array}{l}0.80 \\
0.86\end{array}$ \\
\hline & CK & 611 & 0.76 \\
\hline & LD & 575 & 0.73 \\
\hline & Myoglobin & 267 & 0.75 \\
\hline CK-MB & CK-MM & 350 & -0.77 \\
\hline \multirow[t]{5}{*}{ CK } & Aldolase & 505 & 0.82 \\
\hline & ALT & 612 & 0.70 \\
\hline & AST & 611 & 0.76 \\
\hline & LD & 575 & 0.70 \\
\hline & Myoglobin & 267 & 0.89 \\
\hline Hematocrit & ESR & 604 & -0.58 \\
\hline \multirow[t]{5}{*}{ LD } & Aldolase & 472 & 0.78 \\
\hline & ALT & 576 & 0.67 \\
\hline & AST & 575 & 0.73 \\
\hline & CK & 575 & 0.70 \\
\hline & Myoglobin & 264 & 0.70 \\
\hline \multirow[t]{2}{*}{ Lymphocytes } & Polys & 606 & -0.92 \\
\hline & WBC & 607 & -0.50 \\
\hline \multirow[t]{4}{*}{ Myoglobin } & Aldolase & 177 & 0.82 \\
\hline & ALT & 268 & 0.73 \\
\hline & $\begin{array}{l}\text { AST } \\
\text { LD }\end{array}$ & $\begin{array}{l}267 \\
264\end{array}$ & $\begin{array}{l}0.75 \\
0.70\end{array}$ \\
\hline & CK & 267 & 0.89 \\
\hline \multirow[t]{2}{*}{ Polys } & Lymphocytes & 606 & -0.92 \\
\hline & WBC & 606 & 0.55 \\
\hline \multirow[t]{2}{*}{ WBC } & Lymphocytes & 607 & -0.50 \\
\hline & Polys & 606 & 0.55 \\
\hline
\end{tabular}

* All Spearman Rho rank correlation coefficient p-values were $<0.00005$. Moderately to highly correlated Spearman $r$ values were $\geq 0.50$. Abbreviations: $n$, number of values available for analysis; others as in Table $\mathbf{1 .}$ with fibrotic liver disease of unknown origin, non-alcoholic steatohepatitis, hepatomegaly of unknown cause and hepatitis secondary to blood transfusion).

\section{DISCUSSION}

This study assessed routine laboratory test results in a comparatively large referral population of the IIM at various stages of illness to identify possible associations with disease not previously noted, to determine if laboratory test values vary among gender, racial, age and clinical groups, and to define possible correlations among these tests.

It is commonly accepted that CK, aldolase, ALT, AST, and LD are muscle-derived enzymes in myositis whose levels tend to indicate disease activity [3, 19]. Thus, not surprisingly, patients with PM, who typically have more severe muscle disease, were found to have higher levels of these enzymes than DM patients [1]. Another possible explanation, however, is that patients with DM more frequently have circulating inhibitors or autoantibodies to CK or to other enzymes and these autoantibodies may result in lower serum enzyme levels $[19,20]$.

In terms of the sex differences, males have higher elevations in enzymes (including CK, CK-MB, CK-MM, aldolase and transaminases) compared to females reflecting their greater average muscle mass [21]. The reasons for the lower immunoglobulin levels and lymphocyte counts in men than in women and higher WBCs in men remain unclear. In the general population, men have higher hematocrit levels and lower ESR levels compared to women [22]. Leukocytosis has been associated with low-grade fever at the onset of myositis and in association with disease flares in certain groups [8]. Different tests were also found to vary with respect to race. It had been known that CK levels tend to be higher in blacks than Caucasians, likely as a result of greater muscle mass in the former [13,23].

Regarding the previously unreported abnormalities, although gender was an important determinant of hematocrit, we found that hematocrit is lower in DM than PM. Because PM tends to present with more severe disease activity than DM [1], a lower hematocrit as a result of the anemia of chronic disease might have been expected more often in PM patients. Perhaps because DM has more vasculopathy than PM [1], there might be less capacity to produce red blood cells or more gastrointestinal or other bleeding in DM. The more frequent vasculopathy seen in DM compared to PM [1], with resultant capillary leak in damaged capillaries in muscle and other target organs or abnormal gastrointestinal absorption, may be the etiology of lower serum albumin, which is a negative acute-phase protein, in patients with DM than in PM. Hematocrits were also higher in Caucasians compared to blacks, in patients $>50$ years of age, and in PM. Higher hematocrits were reported in healthy populations of Caucasians compared to blacks in both gender groups, but the same study failed to reveal a major age effect [18].

We also noted significant correlations among various laboratory findings in the IIM. Moderate to high correlations were observed among aldolase and ALT, AST, CK, LD, myoglobin, Polys, and WBC. Thus, muscle enzymes and muscle breakdown products all correlated highly, as 
A.

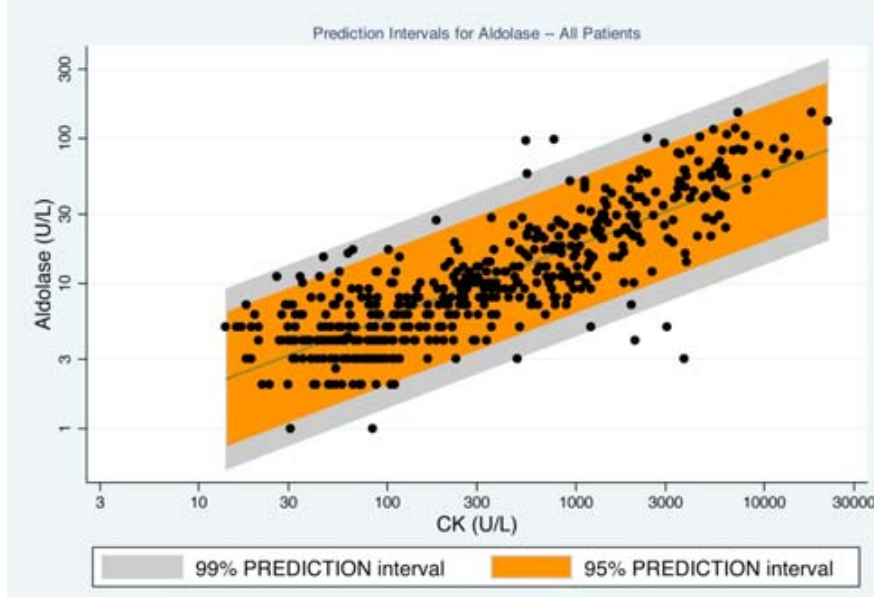

B.

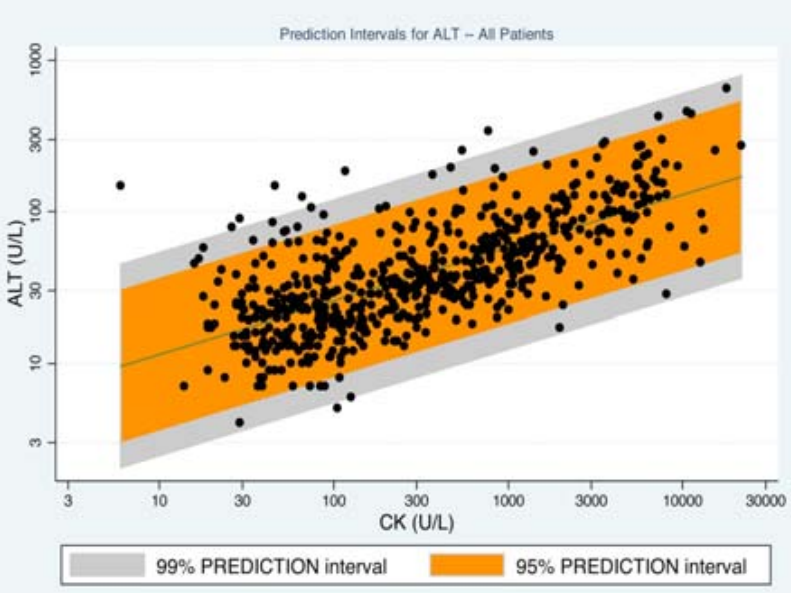

C.

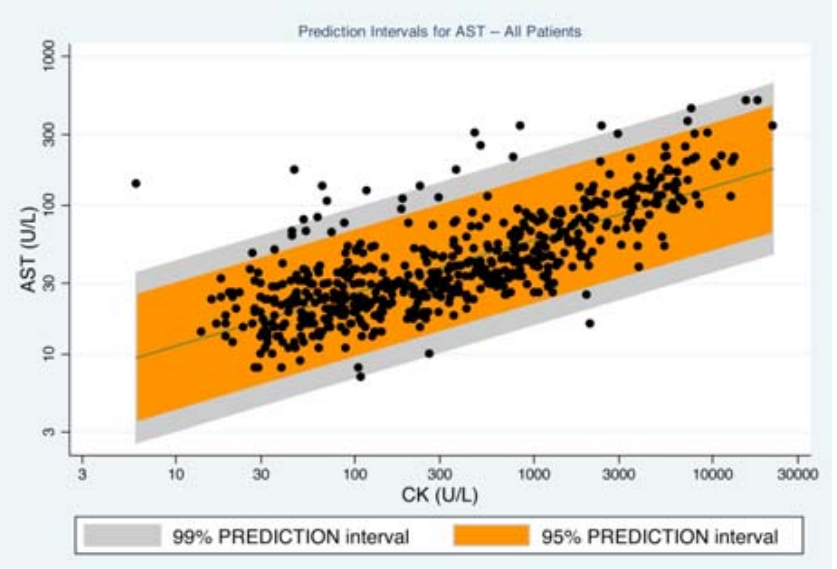

D.

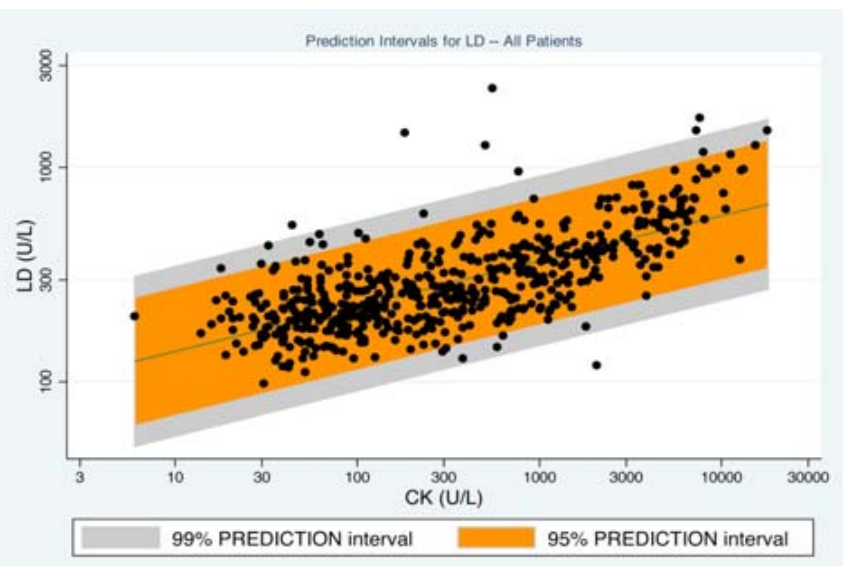

Fig. (4). Scatterplots and the $99 \%$ and $95 \%$ prediction intervals for the relationships among CK and aldolase (A), ALT (B), AST (C) and LD (D) levels*.

*Abbreviations as in Table 1 and Figs. (1-3).

expected. Muscle enzyme levels may be increased in patients with active disease not only due to skeletal muscle inflammation, but also due to release of these enzymes into the peripheral blood by regenerating myoblasts. CK-MB, aldolase, LD and other enzymes are known to be produced by myoblasts [24-27].

The significant but low correlations of WBC and Polys with muscle enzyme levels and muscle metabolites such as myoglobin were unexpected. However, CK is expressed in WBC, including macrophages [28, 29], as well as in endothelial cells [30], and LD is also expressed by $\mathrm{T}$ and $\mathrm{B}$ lymphocytes [31]. Thus, while CK and LD may be increased due to active myositis and may correlate on that basis, there may also be several tissue sources outside the muscle for these enzymes, providing additional rationale for their correlation with WBC and other tests.

Although attempts were made to avoid possible confounding in all aspects of the study, there are limitations to the approaches used in this retrospective investigation. First, the data may not be reflective of a typical IIM population as subjects referred to the NIH may have more severe disease or were taking more medications that could have influenced the laboratory results. Second, missing data were inevitable in this retrospective approach, although adequate numbers existed for nearly all of the studies to allow for an appropriately powered analysis. Additionally, possible factors that could have also impacted the laboratory findings that could not be directly investigated in this retrospective study included: variations in clinical disease activity; the degree of muscle damage; disease duration; myositis autoantibodies; concomitant illnesses; lung or cardiac or other organ system involvement related to myositis; and medications or other treatment regimens. All of these important factors should be included in future prospective investigations in this area.

Nonetheless, this is the first study undertaken to describe the range of common laboratory findings from a comparatively large sample of myositis patients, in various myositis phenotypes, and involving a large number of variables. The results also serve as the foundation for future research in developing guidance to clinicians in diagnosing 
myositis via laboratory tests. The close correlation of some of these tests, particularly CK levels and transaminases, lactate dehydrogenase and aldolase, allow for assessment of the expected ranges of abnormalities and better guidance as to when additional evaluation for possible liver or other disease is indicated.

\section{CONCLUSION}

This study highlights the importance of understanding the range of expected routine laboratory test abnormalities in myositis patients and the differences among subgroups in order to effectively evaluate possible other causes of these abnormalities. Knowledge of the expected range of abnormalities of common laboratory tests may aid in avoiding unnecessary expensive and invasive diagnostic techniques in myositis patients.

\section{ACKNOWLEDGEMENTS}

The authors wish to acknowledge Bhanu Koneru for help in collecting and organizing data, the clinical assistance of Drs. Paul Plotz and Mark Gourley and the useful critical comments of Drs. Elizabeth Adams, Frank Pucino and Kathleen Coyle on the manuscript.

\section{FUNDING SOURCES}

Funding for this project was provided by the intramural programs of the National Institute of Arthritis and Musculoskeletal and Skin Disease and the National Institute of Environmental Health Sciences, and the Clinical Center, NIH, Bethesda, MD.

\section{CONFLICT OF INTEREST}

Declared none.

\section{ABBREVIATIONS}

$$
\begin{array}{ll}
\mathrm{ALT}= & \text { Alanine aminotransferase } \\
\mathrm{AST}= & \text { Aspartate aminotransferase } \\
\mathrm{CK}= & \text { Creatine kinase } \\
\mathrm{CK}-\mathrm{BB}= & \text { Creatine Kinase Isoenzyme Fractions: CK-BB is } \\
& \text { found mostly in the brain and lungs, CK-MB- is } \\
& \text { found mostly in the heart, CK-MM is found } \\
& \text { mostly in skeletal muscle } \\
= & \text { Dermatomyositis } \\
\mathrm{DM}= & \text { Erythrocyte sedimentation rate } \\
\mathrm{ESR}= & \text { Idiopathic inflammatory myopathies } \\
\mathrm{IIM}= & \text { Lactate dehydrogenase } \\
\mathrm{LD}= & \text { Polymorphonuclear leukocytes } \\
\text { Polys }= & \text { Polymyositis } \\
\text { PM }= & \text { White blood cell } \\
\text { WBC } &
\end{array}
$$

\section{REFERENCES}

[1] Miller FW. Inflammatory Myopathies: Polymyositis, dermatomyositis, and related conditions. In: Arthritis and Allied Conditions. W. Koopman and L. Moreland Lippincott Eds. A Textbook of Rheumatology. Philadelphia: Williams and Wilkins 2005: pp 1593-620.

[2] Rider LG, Miller FW. Deciphering the clinical presentations, pathogenesis, and treatment of the idiopathic inflammatory myopathies. J Am Med Assoc 2011; 305(2): 183-90.
[3] Mastaglia FL, Garlepp MJ, Phillips BA, Zilko PJ. Inflammatory myopathies: clinical, diagnostic and therapeutic aspects. Muscle Nerve 2003; 27(4): 407-25.

[4] Munsat TL, Baloh R, Pearson CM, Fowler WJ. Serum enzyme alterations in neuromuscular disorders. J Am Med Assoc 1973; 226: $1536-43$.

[5] Rider LG, Miller FW. Laboratory evaluation of the inflammatory myopathies. Clin Diagn Lab Immunol 1995; 2(1): 1-9.

[6] Bohlmeyer TJ, Wu AH, Perryman MB. Evaluation of laboratory tests as a guide to diagnosis and therapy of myositis. Rheum Dis Clin North Am 1994; 20: 845-56.

[7] Bohan A, Peter JB, Bowman RL, Pearson CM. Computer-assisted analysis of 153 patients with polymyositis and dermatomyositis. Medicine 1977; 56: 255-86.

[8] Miller FW. Polymyositis and Dermatomyositis. In: L Goldman and D Ausiello Eds. Cecil Textbook of Medicine. Philadelphia: Saunders 2004; pp. 1680-4.

[9] Bohan A, Peter JB. Polymyositis and dermatomyositis. Parts 1 and 2. N Engl J Med 1975; 292: 344-7.

[10] Hinkle DE, Wiersma W, Jurs SG. Applied statistics for behavioral sciences. Chicago: Rand McNally 1979.

[11] Diessner GR, Howard FM Jr, Winkelmann RK, Lambert EH, Mulder DW. Laboratory tests in polymyositis. Arch Intern Med 1966; 117: 757-63.

[12] Viguier M, Fouere S, de la Salmoniere P, et al. Peripheral blood lymphocyte subset counts in patients with dermatomyositis: clinical correlations and changes following therapy. Medicine 2003; 82(2): 82-6.

[13] Harris EK, Wong ET, Shaw ST. Statistical criteria for separate reference intervals: race and gender groups in creatine kinase. Clin Chem 1991; 39: 1580-2.

[14] Stranges S, Dorn JM, Muti P, et al. Body fat distribution, relative weight, and liver enzyme levels: a population-based study. Hepatology 2004; 39(3): 754-63.

[15] Ama PF, Simoneau JA, Boulay MR, Serresse O, Theriault G, Bouchard C. Skeletal muscle characteristics in sedentary black and Caucasian males. J Appl Physiol 1986; 61(5): 1758-61.

[16] Saxena S, Wong ET. Heterogeneity of common hematologic parameters among racial, ethnic, and gender subgroups. Arch Pathol Lab Med 1990; 114(7): 715-9.

[17] Gillum RF. A racial difference in erythrocyte sedimentation. J Natl Med Assoc 1993; 85(1): 47-50.

[18] Yip R, Johnson C, Dallman PR. Age-related changes in laboratory values used in the diagnosis of anemia and iron deficiency. Am J Clin Nutr 1984; 39(3): 427-36.

[19] Kagen LJ, Aram S. Creatine kinase activity inhibitor in sera from patients with muscle disease. Arthritis Rheum 1987; 30: 213-7.

[20] Warren GL, O'farrell L, Rogers KR, Billings KM, Sayers SP, Clarkson PM. CK-MM autoantibodies: prevalence, immune complexes, and effect on CK clearance. Muscle Nerve 2006; 34(3): 335-46.

[21] Targoff IN. Laboratory testing in the diagnosis and management of idiopathic inflammatory myopathies. Rheum Dis Clin North Am 2002; 28( 4): 859-90.

[22] International Committee for Standardization in Hematology. Recommendation for measurement of erythrocyte sedimentation rate of human blood. Am J Clin Pathol 1977; 68: 505-7.

[23] Black HR, Quallich H, Gareleck CB. Racial differences in serum creatine kinase levels. Am J Med 1986; 81: 479-87.

[24] Arenas J, Diaz V, Liras G, et al. Activities of creatine kinase and its isoenzymes in serum in various skeletal muscle disorders. Clin Chem 1988; 34: 2460-2.

[25] Apple FS. Tissue specificity of cardiac troponin I, cardiac troponin $\mathrm{T}$ and creatine kinase-MB. Clin Chim Acta 1999; 284(2): 151-9.

[26] Meighan MRL, Tolan DR. Noncoordinate changes in the steadystate mRNA expressed from aldolase A and aldolase $\mathrm{C}$ genes during differentiation of chicken myoblasts. J Cell Biochem 1995; 57(3): 423-31.

[27] Barjot C, Laplace MV, Gannoun ZL, et al. Expression of lactate dehydrogenase, myosin heavy chain and myogenic regulatory factor genes in rabbit embryonic muscle cell cultures. J Muscle Res Cell Motil 1998; 19(4): 343-51.

[28] Loike JD, Kozler VF, Silverstein SC. Creatine kinase expression and creatine phosphate accumulation are developmentally regulated during differentiation of mouse and human monocytes. J Exp Med 1984; 159(3): 746-57. 
[29] DeChatelet LR, McCall CE, Shirley PS. Creatine phosphokinase activity in rabbit alveolar macrophages. Infect Immun 1973; 7(1): 29-34.
[30] Loike JD, Cao L, Brett J, Ogawa S, Silverstein SC, Stern D. Hypoxia induces glucose transporter expression in endothelial cells. Am J Physiol 1992; 263(2): C326-C33.

[31] Ringoir S, Plum J. LDH isozymes of human T and B lymphocytes. Clin Chim Acta 1975; 60 (3): 379-83.

Received: March 25, 2012

(C) Volochayev et al.; Licensee Bentham Open.

This is an open access article licensed under the terms of the Creative Commons Attribution Non-Commercial License (http://creativecommons.org/licenses/by-nc/ $3.0 /$ ) which permits unrestricted, non-commercial use, distribution and reproduction in any medium, provided the work is properly cited. 